\title{
ANALISIS DAYA DUKUNG AIR PADA KAWASAN PERBATASAN NEGARA DI TAU LUBIS / LABANG (LOKPRI LUBIS OGONG) KABUPATEN NUNUKAN PROVINSI KALIMANTAN UTARA
}

\author{
Ernamaiyanti $^{1)}$, Mega Yunanda ${ }^{2)}$ \\ ${ }^{1)}$ Peneliti Ahli Lingkungan \\ ${ }^{2)}$ Dosen Prodi Teknik Sipil Universitas Palembang \\ E-mail : chania.arsy@gmail.com, megayunanda@unpal.ac.id
}

\begin{abstract}
ABSTRAK
Berdasarkan UU Nomor 32 tahun 2009 tentang Pengelolaan Lingkungan Hidup, daya dukung lingkungan hidup adalah kemampuan lingkungan hidup untuk mendukung peri kehidupan manusia dan makhluk hidup lain. Daya dukung air merupakan kemampuan sumberdaya air untuk memenuhi suatu kebutuhan dengan meninjau besarnya ketersediaan air. Data yang digunakan adalah data primer dan data sekunder. Perhitungan daya dukung air pada kajian in imengacu kepada Peraturan Menteri Lingkungan hidup No.17 Tahun 2009 tentang Pedoman Penentuan Daya Dukung Lingkungan Hidup Dalam Penataan Ruang Wilayah. Metode perhitungan daya dukung air di suatu wilayah menggunakan pendekatan ketersediaan dan kebutuhan akan sumber daya air bagi penduduk secara sehat dan layak. Analisis data spasial dilakukan menggunakan perangkat lunak berbasis SIG, sedangkan untuk data nonspasial dianalisis dengan menggunakan perangkat lunak yang memiliki kemampuan kalkulasi dan pembuatan grafik. Hasil analisis terhadap total kebutuhan air di PKSN Tau Lumbis sebanyak $950.400 \mathrm{~m}^{3} /$ tahun, potensi ketersediaan air sebanyak $180.466 .000 \mathrm{~m}^{3} /$ tahun, atau masih surplus sumber daya air bagi penduduk sebesar $179.515 .600 \mathrm{~m}^{3} /$ tahun. Sementara itu, total kebutuhan air di PLBN Labang sebanyak 2.052.800 $\mathrm{m}^{3} /$ tahun, potensi ketersediaan air sebanyak $3.644 .377 .750 \mathrm{~m}^{3} /$ tahun, atau masih surplus sumber daya air bagi penduduk sebesar $362.324 .950 \mathrm{~m}^{3} /$ tahun. Perbandingan kondisi SDLL-Air antara tahun 2020 dan 2040 tidak terjadi perubahan yang signifikan baik di PKSN Tau Lumbis maupun PLBN Labang. SDLL-Air 2020 sampai SDLL-Air 2040 sebagian besar tetap tidak terjadi perubahan yang mendasar.
\end{abstract}

Kata Kunci : Ketersediaan air, kebutuhan air, sumberdaya, surplus.

\section{PENDAHULUAN}

Tau Lumbis (Lokpri Lumbis Ogong) merupakan salah satu pusat pelayanan PKSN dan pintu gerbang, yaitu pusat kegiatan terdepan dalam peningkatan pelayanan pertahanan dan keamanan Negara serta kegiatan lintas batas di Kawasan Perbatasan Negara. Fungsi Tau Lumbis sebagai pusat pelayanan kepabeanan, imigrasi, karantina dan keamanan, pusat kegiatan pertahanan dan keamanan negara, pusat pelayanan pendidikan dan kesehatan, pusat perdagangan dan jasa lintas Negara, dan simpul transportasi tersier di kawasan perbatasan.
Permasalahan yang terdapat di Lokpri Lumbis Ogong salah satunya ketidak seimbangan ketersediaan air dan kebutuhan air (Notulensi Rapat I Penyusunan Materi Teknis RDTR Kawasan Perbatasan Negara di Tau Lumbis / Labang (LokpriLumbisOgong), Kabupaten Nunukan Provinsi Kalimantan Utara, 21 Juli 2019). Ketidakseimbangan antara ketersediaan air dengan kebutuhan air di lapangan seringkali terjadi di kehidupan sehari-hari. Ketersediaan air terus menurun sementara permintaan air terus meningkat. Berdasarkan undang-undang tentang Sumberdaya Air, untuk menangani 
ketidakseimbangan air antara ketersediaan air dan kebutuhan air harus dikelola dengan baik dengan mempertimbangkan fungsi lingkungan sosial dan ekonomi (Haryanto, 2013).

Status daya dukung lingkungan dengan pendekatan air menunjukkan suatu kondisi ketersediaan air wilayah dengan kebutuhan yang ada. Pengelolaan air yang kurang tepat menimbulkan dampak negatif terhadap ketersediaan air. Hal ini juga dapat menimbulkan bencana lingkungan (banjir) apabila daya dukung lingkungan terhadap air terlampaui (Samekto dan Winata, 2010). Kasus inilah yang sering terjadi di LokpriLumbisOgong, apabila musim kemarau terjadi kekeringan dan musim hujan dengan deebit tinggi terjadi banjir (Notulensi Rapat I Penyusunan Materi Teknis RDTR Kawasan Perbatasan Negara di Tau Lumbis / Labang (LokpriLumbisOgong), Kabupaten Nunukan Provinsi Kalimantan Utara, 21 Juli 2019).

Tujuan dilaksanakan penelitian ini yaitu untuk menganalisis status daya dukung lingkungan berdasarkan ketersedian dan kebutuhan air di LokpriLumbisOgong tahun 2020 dan prediksinya tahun 2040, sesuai Rencana Detai Tata Ruang (RDTR) Kawasan Perbatasan Negara di Tau Lumbis/Labang (LokpriLumbisOgong) Kabupaten Nunukan, Provinsi Kalimantan Utara.Hasil penentuan penghitungan daya dukung lingkungan dengan pendekatan kebutuhan dan ketersediaan air dapat dijadikan acuan dalam penelitian lanjutan dengan variabel yang lebih banyak dan skala yang lebih detail, sehingga dapat dijadikan rekomendasi dalam penyusunan RDTR yang berkelanjutan di Tau Lumbis/Labang (LokpriLumbisOgong) Kabupaten Nunukan, Provinsi Kalimantan Utara.

\section{TINAJUAN PUSTAKA Status Daya Dukung Lingkungan}

Penentuan daya dukung lingkungan dengan pendekatan air (DDL-Air) dapat ditentukan setelah diketahui besarnya ketersediaan air dan kebutuhan air pada daerah penelitian. Perbandingan antara kondisi ketersediaan air dengan kebutuhan air pada wilayah penelitian menjadi dasar dalan penetapan status daya dukung lingkungan. Kriteria penetapan status DDL-Air yang digunakan berdasarkan Prastowo (2010), yaitu:

1. Rasio supply/demand >2 Daya dukung lingkungan aman (sustain)

2. Rasio supply/demand 1-2 Daya dukung lingkungan aman bersyarat (conditional sustain)

3. Rasio supply/demand < 1 Daya dukung lingkungan telah terlampaui (overshoot).

Analisis data spasial dilakukan menggunakan perangkat lunak berbasis SIG, sedangkan untuk data nonspasial dianalisis dengan menggunakan perangkat lunak yang memiliki kemampuan kalkulasi dan pembuatan grafik. Pengolahan data nonspasial dilakukan untuk menghitung koefisien limpasan, ketersediaan air, memproyeksikan data penentu kebutuhan air (jumlah penduduk), kebutuhan air, dan untuk mengetahui rasio dan status daya dukung lingkungan tahun 2020dan prediksinya tahun 2040. Analisis selanjutnya dengan membandingkan hasil penghitungan dengan data hasil pengamatan di lapangan untuk melihat korelasi antara status daya dukung lingkungan berdasarkan pendekatan ketersediaan dan kebutuan air dengan kejadian banjir dan kekeringan. Proses analisis disajikan dengan diagram alir pada Gambar di bawah ini. 


\section{Gambar 1}

\section{Status daya dukung lingkungan dengan pendekatan ketersediaan dan kebutuhan air}

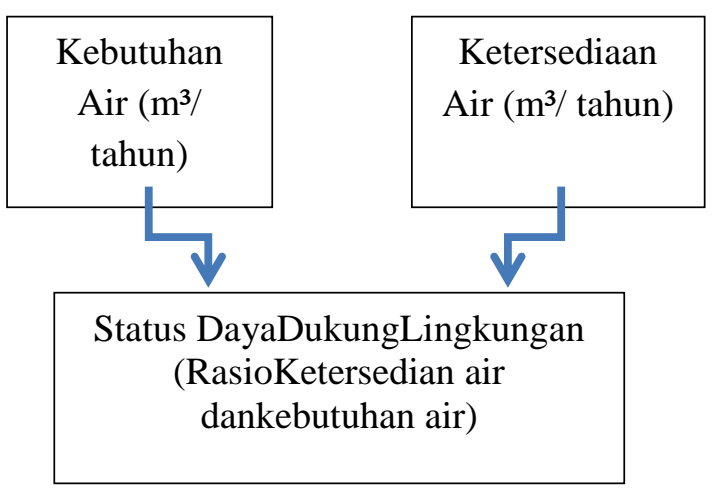

\section{METODOLOGI PENELITIAN}

Data yang digunakan dalam penelitian ini yaitu data primer yang diperoleh dari hasil lapangan berupa dokumentasi dan wawancara dengan pihak terkait serta data sekunder. Pengumpulan data sekunder antara lain: data jumlah penduduk Peta Rupa Bumi Indonesia, Peta penggunaan lahan skala 1:5.000, Peta Rencana Detail Tata Ruang skala 1:5.000 dan Data Curah hujan bulanan Kabupaten Nunukan.

Perhitungan daya dukung air pada kajian ini mengacu kepada Peraturan Menteri Lingkungan hidup No.17 Tahun 2009 tentang Pedoman Penentuan Daya Dukung Lingkungan Hidup Dalam Penataan Ruang Wilayah. Metode perhitungan daya dukung air di suatu wilayah menggunakan pendekatan ketersediaan dan kebutuhan akan sumber daya air bagi penduduk secara sehat dan layak.

Perhitungan ketersediaan air dengan menggunakan Metode Koyang dimodifikasi dari metode rasional dengan mempertimbangkan curah hujan tahunan, dan tutupan lahan dengan menggunakan persamaan sebagai berikut:

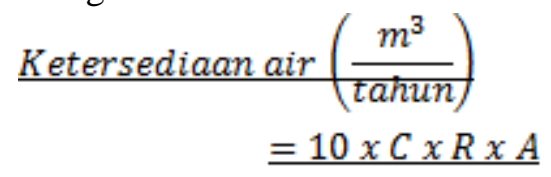

Dimana:

$\mathrm{C}=$ koefisienlimpasantertimbang

$\mathrm{R}=$ rata-rata curah hujan tahunan wilayah (mm/tahunan)

$\mathrm{A}=$ luas wilayah (ha)

$10=$ factor konversi dari mm.ha menjadi $\mathrm{m}^{3}$

Kriteria yang digunakan dalam menilai tingkat ketersediaan air di PSBN Tau Lumbisdan PLBN Labang menggunakan 4 kategori yaitu: sumberdaya air yang sangat tersedia (>50juta $\mathrm{m}^{3} /$ tahun); sumberdaya air sangat tersedia (30-50 juta $\mathrm{m}^{3} /$ tahun); sumberdaya air tersedia cukup tersedia (10-30 juta $\mathrm{m}^{3} /$ tahun), sumberdaya air kurang tersedia( $<10$ juta $\mathrm{m}^{3} /$ tahun $)$.

Perhitungan kebutuhan air penduduk menggunakan metode yang terdapat dalam Permen LH Nomor 17 Tahun 2009, dengan menggunakan persamaan sebagai berikut:

Ketersediaan air $\left(\frac{m^{3}}{\text { tanun }}\right)=N \times K H L A$

Keterangan:

$\mathrm{N}=$ Jumlah penduduk (orang)

KHLA = Kebutuhan air untuk hidup layak

$=1600 \mathrm{~m}^{3}$ air $/$ kapita/tahun,

$=2 \times 800 \mathrm{~m}^{3}$ air $/$ kapita/tahun, dimana: $800 \mathrm{~m}$ kebutuhan air untuk keperluan domestik 2 merupakan factor koreksi yang mencakup kebutuhan pangan, domestic dan lainnya.

Kriteria yang digunakan dalam menilai tingkat kebutuhan air bagi penduduk di di PKSN Tau Lumbisdan PLBN Labang menggunakan 4 kategori yaitu: kebutuhan air sangat tinggi ( $>50$ juta $\mathrm{m}^{3} /$ tahun); kebutuhan air tinggi (30-50 juta $\mathrm{m}^{3} /$ tahun); kebutuhan air sedang (10-30 juta $\mathrm{m}^{3} /$ tahun), kebutuhan air sedikit ( $<10$ juta $\mathrm{m}^{3} /$ tahun).

\section{HASIL DAN PEMBAHASAN}

Penilaian daya dukung sumber daya air pada suatu wilayah adalah tersedianya potensi sumber daya air yang dapat 
dimanfaatkan oleh makhluk hidup yang ada dalam wilayah tersebut. Perhitungan daya dukung sumberdaya air di suatu wilayah surplus menunjukkan bahwa ketersediaan air di suatu wilayah tercukupi, sedangkan keadaan defisit menunjukkan bahwa wilayah tersebut tidak dapat memenuhi kebutuhan akan air. Guna memenuhi kebutuhan air, fungsi lingkungan yang terkait dengan sistem tata air harus dilestarikan.

Hasil perhitungan didapat ketersediaan air di PKSN Tau Lumbis Tahun 2019 dan PLBN Labang Tahun 2019 kategori sangat tinggi, masing-masing adalah 180.466 .000 $\mathrm{m}^{3} /$ tahun dan 3.644.377.750 $\mathrm{m}^{3} /$ tahun. Geohidrologi sudah memperlihatkan ketersediaan air. Ketersediaan air sangat tinggi artinya ketersediaan air tanah dalam dan dangkal cukup banyak. Sementara ketersediaan air sedang artinya air tanah dangkal tak cukup banyak tapi air tanah dalamnya banyak.

Berdasarkan hasil analisa, kelas SKL ketersediaan air tinggi mendominasi wilayah perencanaan dengan luas 772,63atau 58,31\%. Untuk lebih jelasnya mengenai luas dan sebaran SKL ketersediaan air dapat dilihat pada tabel berikut.

Tabel 1

SKL Ketersediaan Air Kawasan Perencanaan

\begin{tabular}{|c|l|c|c|c|c|c|c|}
\hline \multirow{2}{*}{ No. } & \multirow{2}{*}{$\begin{array}{c}\text { KKL } \\
\text { Ketersediaan } \\
\text { Air }\end{array}$} & \multicolumn{2}{|c|}{ Labang } & \multicolumn{2}{c|}{ Tau Lumbis } & \multicolumn{2}{c|}{ Jumlah } \\
\cline { 3 - 8 } & $\begin{array}{c}\text { Luas } \\
(\mathbf{H a})\end{array}$ & $\%$ & $\begin{array}{c}\text { Luas } \\
\text { (Ha) }\end{array}$ & $\%$ & $\begin{array}{c}\text { Luas } \\
(\mathbf{H a})\end{array}$ & $\%$ \\
\hline 1 & $\begin{array}{l}\text { Ketersediaan } \\
\text { Air Tinggi }\end{array}$ & 269,38 & 40,28 & 503,25 & 76,69 & 772,63 & 58,31 \\
\hline 2 & $\begin{array}{l}\text { Ketersediaan } \\
\text { Air Sedang }\end{array}$ & 395,35 & 59,12 & 123,96 & 18,89 & 519,31 & 39,19 \\
\hline 3 & $\begin{array}{l}\text { Ketersediaan } \\
\text { Air Rendah }\end{array}$ & 4,04 & 0,60 & 29,03 & 4,42 & 33,07 & 2,50 \\
\hline \multicolumn{1}{|c|}{ TOTAL } & 668,77 & 100,00 & 656,24 & 100,00 & $1.325,01$ & 100,00 \\
\hline
\end{tabular}

Sumber: HasilAnalisa 2019

Hasil analisis terhadap total kebutuhan air di PKSN Tau Lumbis sebanyak 950.400 $\mathrm{m}^{3} /$ tahun, potensi ketersediaan air sebanyak $180.466 .000 \mathrm{~m}^{3} /$ tahun, atau masih surplus sumberdaya air bagi penduduk sebesar 179.515.600 $\mathrm{m}^{3} /$ tahun. Sementara itu, total kebutuhan air di PLBN Labang sebanyak $2.052 .800 \mathrm{~m}^{3} /$ tahun, potensi ketersediaan air sebanyak $3.644 .377 .750 \mathrm{~m}^{3} /$ tahun, atau masih surplus sumberdaya air bagi penduduk sebesar $362.324 .950 \mathrm{~m}^{3} /$ tahun.

Air bersih juga merupakan salah satu manfaat yang dapat diperoleh dari ekosistem. Secara alami, air bersih dapat berasa dari air permukaan, seperti: sungai dan danau maupun berasal dari air tanah.

\section{Gambar 2}

\section{Jasa Ekosistem Penyedia Air di PKSN Tau Lumbis}

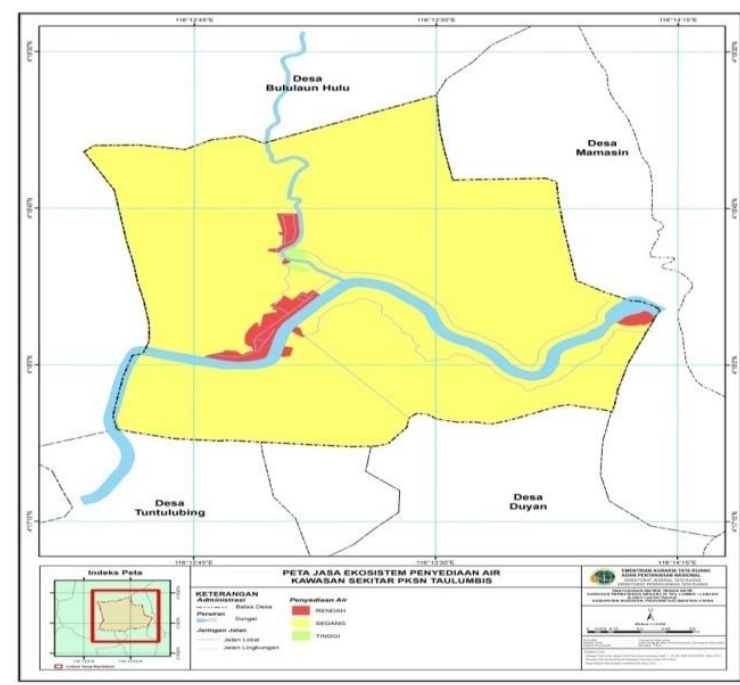

Sumber: Analisis GIS, 2019

Tabel 2

Jasa EkosistemPenyedia Air di PKSN Tau Lumbis

\begin{tabular}{|c|c|c|c|c|c|}
\hline \multirow{2}{*}{ No } & \multirow{2}{*}{ DAERAH } & \multicolumn{4}{|c|}{ JE PENYEDIAAN AIR } \\
\cline { 3 - 6 } & & RENDAH (Ha) & SEDANG (Ha) & TINGGI(Ha) & Total \\
\hline 1 & Tau Lumbis & 16,87 & 631,54 & 1,63 & 650,04 \\
\hline \multicolumn{2}{|c|}{ Persentase } & $2,60 \%$ & $97,15 \%$ & $0,25 \%$ & $100 \%$ \\
\hline
\end{tabular}

Sumber: Analisis GIS, 2019

Jasa ekosistem penyedia air di PKSN

Tau Lumbis terdiri dari tiga kategori yaitu:

- Kategori rendah seluas 16,87 Ha atau $2,60 \%$

- Kategori sedang seluas 631,54 atau $97,15 \%$

- Kategori tinggi seluas $1,63 \mathrm{Ha}$ atau $0,25 \%$

Artinya PKSN Tau Lumbis masih cukup sebagai penyedia air untuk masyarakatnya. 
Gambar3

Jasa Ekosistem Penyedia Air di PLBN Labang

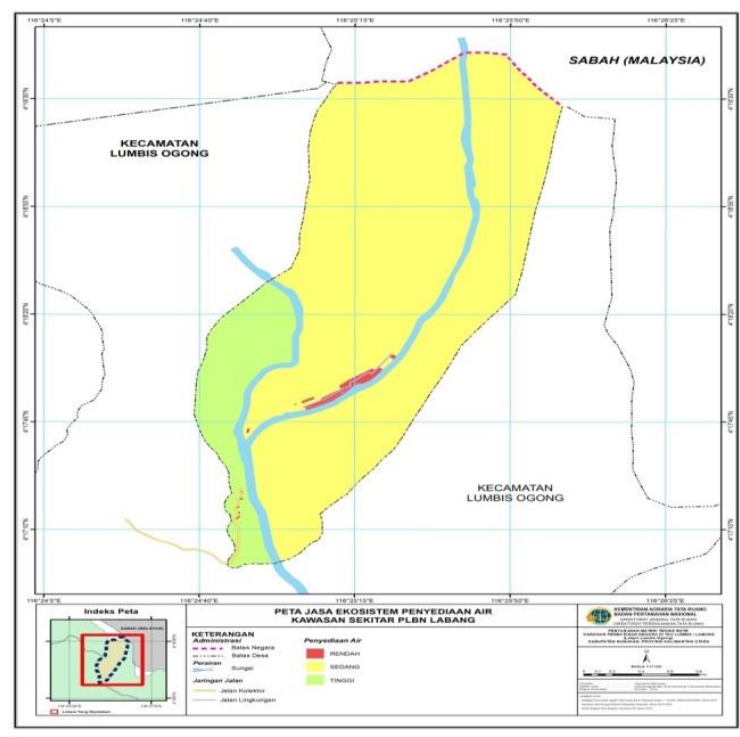

Sumber: Analisis GIS, 2019

Tabel3

Jasa EkosistemPenyedia Air di PLBN

Labang

\begin{tabular}{|c|c|c|c|c|c|}
\hline \multirow{2}{*}{ No } & \multirow{2}{*}{ Daerah } & \multicolumn{4}{|c|}{ JE PENYEDIAAN AIR } \\
\cline { 3 - 6 } & & Rendah (Ha) & Sedang (Ha) & Tinggi(Ha) & Total \\
\hline \multirow{2}{*}{1} & Labang & 5,15 & 577,04 & 85,91 & 668,1 \\
\multicolumn{2}{|c|}{ Persentase } & $0,77 \%$ & $86,37 \%$ & $12,86 \%$ & $100 \%$ \\
\hline
\end{tabular}

Sumber: Analisis GIS, 2019

Jasa ekosistem penyedia air di PLBN Labang terdiri daritigakategoriyaitu:

- Kategori rendah seluas 5,15 Ha atau 0,77\%

- Kategori sedang seluas 577,04 atau 86,37\%

- Kategori tinggi seluas 85,91 Ha atau $12,86 \%$

Artinya PLBN Labang masih cukup sebagai penyedia air untuk masyarakatnya.

\section{Status Daya Dukung Lingkungan}

Analisis status daya dukung lingkungan dengan pendekatan air (SDDL-Air) merupakan rasio antara kondisi ketersediaan air dengan kebutuhan air yang ada di suatu wilayah. Semakin tinggi nilai ketersediaan air maka nilai rasio akan semakin besar, yang menunjukkan semakin terjaminnya kondisi ketersediaan sumberdaya air untuk memenuhi kebutuhan masyarakat. Berdasarkan perbandingan ini didapatkan rasio SDDL-Air selama tahun perencanaan.

\section{Gambar4}

\section{Rasio Daya Dukung Lingkungan Air di} PKSN Tau Lumbis

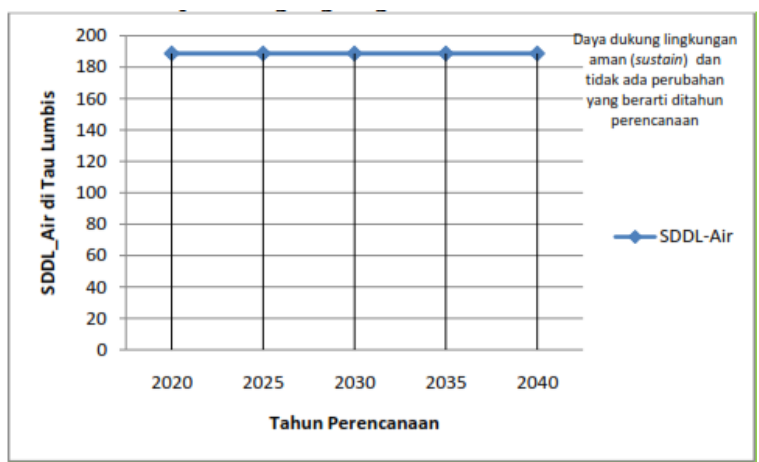

Sumber: HasilAnalisis, 2019

\section{Gambar5}

Rasio Daya Dukung Lingkungan Air di PLBN Labang

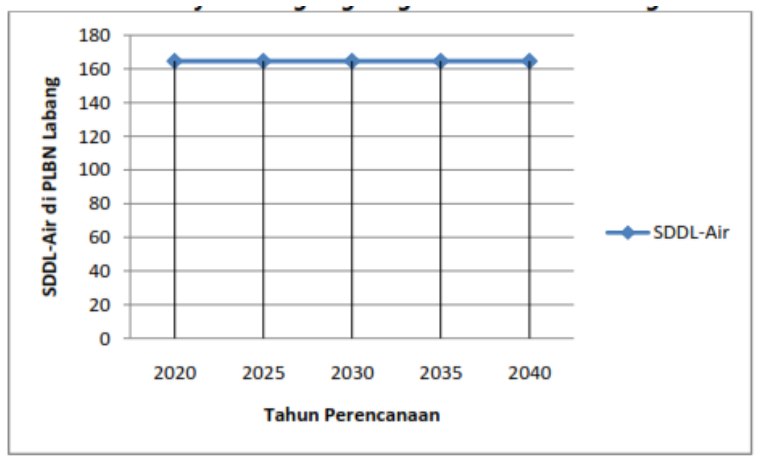

Sumber: HasilAnalisis, 2019

Perbandingan kondisi SDLL-Air antara tahun 2020 dan 2040 tidak terjadi perubahan yang signifikan baik di PKSN Tau Lumbis maupun PLBN Labang. SDLL-Air 2020 yang ditunjukkan dalam gambar dengan SDLL-Air 2040 sebagian besar tetap tidak terjadi perubahan yang mendasar.

\section{KESIMPULAN}

Hasil analisis terhadap total kebutuhan air di PKSN Tau Lumbis sebanyak 950.400 $\mathrm{m}^{3} /$ tahun, potensi ketersediaan air sebanyak $180.466 .000 \mathrm{~m}^{3} /$ tahun, atau masih surplus sumberdaya air bagi penduduk sebesar $179.515 .600 \mathrm{~m}^{3} /$ tahun. Sementara itu, total kebutuhan air di PLBN Labang sebanyak $2.052 .800 \mathrm{~m}^{3} /$ tahun, potensi ketersediaan air sebanyak $3.644 .377 .750 \mathrm{~m}^{3} /$ tahun, atau masih surplus sumberdaya air bagi penduduk sebesar $362.324 .950 \mathrm{~m}^{3} /$ tahun. 
Perbandingan kondisi SDLL-Air antara tahun 2020 dan 2040 tidak terjadi perubahan yang signifikan baik di PKSN Tau Lumbis maupun PLBN Labang. SDLL-Air 2020 sampai SDLL-Air 2040 sebagian besar tetap tidak terjadi perubahan yang mendasar.

\section{DAFTAR PUSTAKA}

Haryanto TE, Fathurrazie S, Rudy S, Zaenal K. 2013. Actual Water Availability and Water Needs in Irrigation Area of Riam Kanan in South Kalimantan Province. Academic Research International. Vol. 4 No. 6 November 2013

Laporan Akhir Rencana Perlindungan dan Pengelolaan Lingkungan Hidup (RPPLH) Kabupaten Nunukan Tahun 2017 - 2047. Pusat Studi Lingkungan Hidup, Universitas Gadjah Mada, Yogyakarta

NotulensiRapat I Penyusunan Materi Teknis RDTR KawasanPerbatasan Negara di Tau Lumbis / Labang (LokpriLumbisOgong), Kabupaten Nunukan Provinsi Kalimantan Utara, 21 Juli 2019

Peraturan Menteri Negara Lingkungan Hidup Nomor 17 Tahun 2009 Tentang Pedoman Penentuan Daya Dukung Lingkungan Hidup Dalam Penataan Ruang Wilayah

Prastowo. 2010. Daya Dukung Lingkungan Aspek Sumberdaya Air . Working Paper P4W. Bogor (ID): Crestpent Press.

Samekto C dan Winata E.S. 2010.Potensi Sumber Daya Air di Indonesia. Seminar Nasional: Aplikasi Teknologi Penyediaan Air Bersih untuk Kabupaten/ Kota di Indonesia, PTLBPPT: Jakarta, 16 Juni 2010.

Triatmodjo, B. 2016. Hidrologi Terapan. Beta

Offset. Yogyakarta 